\title{
Вплив вправ кросфіту на рівень фізичної підготовленості школярів старшого шкільного віку
}

Ангеліна Петрова

Харківська державна академія фізичної культури, Харків, Україна

Мета: визначити ступінь зміни рівня фізичної підготовленості школярів 10-11-х класів під впливом вправ кросфіту.

Матеріал і методи: теоретичний аналіз і узагальнення науково-методичної літератури; педагогічне тестування, педагогічний експеримент та методи математичної статистики. Для визначення рівня фізичної підготовленості школярів 10-11-х класів використовувалися тести: піднімання прямих ніг у висі (кількість разів); біг на місці з інтенсивністю 70\% від максимальної до вираженого стомлення (c); «човниковий» біг 449 м (с); біг на 60 м (с) та поперечний шпагат (см). Досліджувані результати порівнювалися з нормами і оцінювалися певною кількістю балів. Статистичний аналіз: матеріали дослідження оброблялися з використанням ліцензованої програми ЕхсеІ. У дослідженні взяли участь 113 школярів 10-11-х класів.

Результати: на початку навчального року здійснено констатувальне дослідження, згідно якого встановлено «середній» рівень (3 бали) фізичної підготовленості у школярів 16-17-ти років. За результатами первинного дослідження учнів було розподілено на основні та контрольні групи для проведення формувального експерименту. Школярі контрольних груп займалися лише за загальноприйнятою державною програмою з фізичної культури для 10-11 класів закладів загальної середньої освіти, а навчальний процес з фізичного виховання школярів основних груп був доповнений варіативним модулем «Кросфіт». Згідно досліджень, які отримані після проведення педагогічного експерименту встановлено, що у школярів основних груп рівень фізичної підготовленості підвищився 3 «середнього» рівня до «вище за середній» та став дорівнювати 4 бали. У досліджуваних контрольних групах зміни на оціночній шкалі не виявлені. У віковому аспекті спостерігається в основному покращення результатів з віком, як у школярів основних, так і контрольних груп (p>0,05). За статтю виявлено, переважно, достовірне превалювання даних юнаків над показниками дівчат ( $p<0,05-0,001)$.

Висновки: виявлено позитивний вплив вправ кросфіту на рівень фізичної підготовленості учнів 10-11-х класів основних груп.

Ключові слова: варіативний модуль, кросфіт, учні старших класів, фізична підготовленість, уроки фізичної культури, рухова активність.

\section{Вступ}

На сьогоднішній день існує проблема зниження рівня фізичної підготовленості, і як наслідок здоров'я учнівської молоді. Низка провідних фахівців [2; 6; 10; 11] зазначають, що за статистичними даними майже $60 \%$ дітей старшого шкільного віку мають відхилення у стані здоров'я та низький рівень фізичної підготовленості. Основними причинами зазначеної проблеми є особливості навчання в сучасній школі, а саме: зростання обсягу навчальної інформації, інтенсифікація проходження матеріалу, модернізація та ускладнення навчальних програм. Все це призводить до збільшення розумового навантаження та зменшення рухової активності дітей [5].

Фізичні вправи є ефективними засобами компенсації дефіциту рухової активності сучасного учня [2]. Однак, згідно з результатами низки авторів [1; 3; 15; $19 ; 22$; 24], на сьогоднішній день діючи уроки малоефективні, одноманітні, не достатньо стимулюють школярів до фізкультурно-спортивної діяльності. Тому означена проблема вимагає пошуку нових цікавих форм, інноваційних засобів, методів та принципів вдосконалення системи фізичного виховання, збільшення обсягу та урізноманітнення видів рухової активності $[1 ; 2 ; 4 ; 10]$.

Ряд науковців приділяють значну увагу питанню оптимізації змістовної сторони уроків фізичної культури [2; $11 ; 20 ; 21 ; 23 ; 25]$. Чисельними дослідженнями визначено позитивний вплив різноманітних видів рухової діяльності на фізичну підготовленість учнів різного вікового періоду. Так, Н. Базилевич, О. Тонконог (2017) виявили покращення рівня фізичної підготовленості молодших школярів під впливом засобів фітбол-аеробіки; Т. М. Бала, І. П. Масляк (2014) встановили позитивну динаміку показників рівня розвитку бистроти під впливом вправ чирлідингу у школярів 5-6-х класів; Т. І. Суворова, 
М. С. Мороз, А. Г. Карабанов (2011) з'ясували, що під впливом занять з атлетичної гімнастики відображається тенденція до покращення даних фізичної підготовленості у школярів старшого шкільного віку. Слід зазначити, що аналіз літературних джерел показав відсутність наукових робіт, які б порушували питання про вплив вправ кросфіту на рівень фізичної підготовленості учнів старшої школи. Таким чином, вищезазначене свідчить про актуальність та доцільність проведення дослідження.

Мета дослідження - визначити ступінь зміни рівня фізичної підготовленості школярів 10-11-х класів під впливом вправ кросфіту.

Зв'язок роботи із науковими програмами, планами, темами. Дослідження проводилося відповідно до ініціативної теми науково-дослідної роботи «Вдосконалення процесу фізичного виховання в навчальних закладах різного профілю» на 2015-2020рр. (номер державної реєстрації 0115U006754) та відповідно до ініціативної теми науково-дослідної роботи «Вдосконалення процесу фізичного виховання різних верств населення» на 20202026 рр. (номер державної реєстрації 0120U101110).

\section{Матеріал і методи дослідження}

У ході експерименту використовувались наступні методи: теоретичний аналіз і узагальнення науково-методичної літератури; педагогічне тестування, педагогічний експеримент та методи математичної статистики.

Для визначення рівня розвитку фізичних якостей школярів 10-11-х класів використовувалися тести, представлені Л. П. Сергієнком [13; 14] та В. А. Романенком [12], а саме: піднімання прямих ніг у висі (кількість разів); біг на місці з інтенсивністю 70\% від максимальної до вираженого стомлення (с); «човниковий» біг 449 м (c); біг на 60 м (с) та поперечний шпагат (см).

Статистичний аналіз: матеріали дослідження оброблялися з використанням ліцензованої програми Excel. Обчислювалися: середнє арифметичне варіаційного ряду $(\bar{X})$ - для оцінки рівня розвитку досліджуваної ознаки; похибка репрезентативності $(\mathrm{m})$ - для визначення відхилення середньої арифметичної від відповідних параметрів генеральної сукупності; достовірність відмінностей (р) - вираховувалась 3 метою встановлення однорідності контрольних та основних груп, ступеню відмінностей показників у віковому аспекті та зміни середніх величин досліджуваних параметрів у основних і контрольних групах після проведення експерименту за допомогою параметричного критерію Стьюдента (t) при рівні значущості не нижче 0,05.

Дослідження проводилось на базі загальноосвітніх шкіл № 146 та № 57 м.Харкова впродовж 2017-2018 навчального року. У ньому брало участь 113 школярів 1617 років, з яких було сформовано 2 основні та 2 контрольні групи. Основні групи включали 59 школярів: перша група - хлопці та дівчата 16 років (n=27), друга група - хлопці та дівчата 17 років $(\mathrm{n}=32)$; контрольні групи включали 54 школярів: перша група - хлопці та дівчата 16 років ( $n=21)$ та друга група - хлопці та дівчата 17 років $(\mathrm{n}=33)$. Всі діти, які брали участь у дослідженні, були практично здорові та знаходилися під наглядом шкільного лікаря.

У ході дослідження школярі контрольних груп займалися лише за загальноприйнятою державною програмою з фізичної культури для 10-11 класів закладів загальної середньої освіти, а навчальний процес з фізичного виховання школярів основних груп був доповнений розробленим нами варіативним модулем «Кросфіт». Заняття 3 кросфіту проводилися два рази на тиждень згідно з розкладом школи. До змісту якого входили теоретичні відомості, спеціальна фізична підготовка (елементи гімнастики, легкої та важкої атлетики, гирьовий спорт, загальнорозвивальні вправи) та технічна підготовка (спеціально підібрані вправи кросфіту: «Burpee», «Box Jump», «Farmer's Walk», «Good morning», «Bear crawl», «Floor wipers», «Burpee bench jump» тощо). Наприкінці вивчення модуля «Кросфіт» учні виконували комплекс вправ у полегшених умовах, який складався зі спеціальних та технічних елементів кросфіту, за мінімальний проміжок часу та із зазначеною кількістю раундів («Cindy», «Annie», «Fran» тощо) [16].

Під час занять враховувалися вікові, статеві та анатомо-фізіологічні особливості учнів. Навантаження та дозування збільшувалось поступово з урахуванням індивідуальних можливостей школярів. Також вправи кросфіту включалися в підготовчу частину уроку інших варіативних модулів, в систему організованих перерв і давалися у вигляді домашніх завдань.

\section{Результати дослідження}

Результати дослідження вказують на відсутність достовірних відмінностей між показники, які досліджувались.

У віковому аспекті визначено здебільшого покращення результатів з віком, як у школярів основних, так і контрольних груп.

Порівнюючи результати за статтю, виявлено, в основному, достовірне превалювання даних юнаків над показниками дівчат ( $p<0,05-0,001)$, за винятком результатів поперечного шпагату, де спостерігається протилежна тенденція, тобто показники дівчат кращі за дані юнаків, і ці зміни, в основному, достовірні ( $p<0,05-0,01)$.

Визначаючи рівень фізичної підготовленості учнів старшого шкільного віку, виявлено, що результати констатувального експерименту свідчать про те, що у школярів досліджуваних груп він відповідає оцінці 3 бали, що вказує на «середній» рівень. Так, за даними рівня розвитку сили в середньому спостерігається оцінка - 2 бали («нижче за середній» рівень); витривалості - 3 бали («нижче за середній» рівень); спритності - 3 бали («середній» рівень); швидкісних здібностей - 2 бали («нижче за середній» рівень); гнучкості - 3 бали («середній» рівень).

Після впровадження експериментальної методики виявлено суттєве покращення за всіма досліджуваними показниками, як у хлопців, так і у дівчат основних груп (табл. 1), і ці відмінності статистично достовірні ( $p<0,05-$ 0,001). Так, приріст результатів, що відображають рівень розвитку сили у юнаків 10-го класу, склав - 24,5\%, 11-го класу - 23,7\%; у дівчат відповідно - 55,3\% та 43,3\%; витривалості - у юнаків 10-го класу становить 7,8\%, 11-го класу - 6,4\%; у дівчат відповідно 25,6\% та 21,4\%; спритності - у юнаків 10-го класу становить 3,1\%, 11-го класу - 8,0\%; у дівчат відповідно 3,0\% та 3,5\%; швидкісних здібностей - у юнаків 10-го класу становить 3,1\%, 11-го класу - 2,1\%; у дівчат відповідно 9,5\% та 3,0\%; гнучкості - у юнаків 10-го класу становить 10,6\%, 11-го класу 10,2\%; у дівчат відповідно 24,2\% та 13,4\%.

Аналізуючи досліджувані показники у віковому та статевому аспектах, отриманих після застосування 
Таблиця 1 Показники рівня фізичної підготовленості учнів основних груп до та після експерименту

\begin{tabular}{|c|c|c|c|c|c|c|}
\hline \multirow{3}{*}{ Класи } & \multirow{3}{*}{ Стать } & & Гру & & \multirow{3}{*}{$\mathrm{t}$} & \multirow{3}{*}{$\mathrm{p}$} \\
\hline & & $\mathrm{n}$ & До експерименту & Після експерименту & & \\
\hline & & \multicolumn{3}{|c|}{ Показники $\bar{X} \pm \mathrm{m}$} & & \\
\hline \multicolumn{7}{|c|}{ Піднімання прямих ніг у висі (кількість разів) } \\
\hline \multirow{2}{*}{10 клас } & Хлопці & 17 & $14,35 \pm 1,74$ & $17,88 \pm 2,11$ & 4,07 & $<0,001$ \\
\hline & Дівчата & 12 & $7,83 \pm 1,93$ & $12,17 \pm 2,06$ & 6,39 & $<0,001$ \\
\hline \multirow{2}{*}{11 клас } & Хлопці & 10 & $16,00 \pm 2,35$ & $19,80 \pm 1,53$ & 2,03 & $>0,05$ \\
\hline & Дівчата & 22 & $9,86 \pm 0,99$ & $14,14 \pm 0,93$ & 7,98 & $<0,001$ \\
\hline \multicolumn{7}{|c|}{ Біг на місці з інтенсивністю 70\% від максимальної до вираэсеного стомлення (с) } \\
\hline \multirow{2}{*}{10 клас } & Хлопці & 17 & $116,08 \pm 2,79$ & $125,20 \pm 1,00$ & 4,79 & $<0,001$ \\
\hline & Дівчата & 12 & $34,14 \pm 1,98$ & $42,90 \pm 1,21$ & 8,89 & $<0,001$ \\
\hline \multirow{2}{*}{11 клас } & Хлопці & 10 & $131,16 \pm 1,83$ & $139,59 \pm 0,66$ & 4,90 & $<0,001$ \\
\hline & Дівчата & 22 & $33,09 \pm 1,31$ & $40,17 \pm 2,29$ & 4,48 & $<0,001$ \\
\hline \multicolumn{7}{|c|}{ «Човниковий» біг $4 \times 9$ м (c) } \\
\hline \multirow{2}{*}{10 клас } & Хлопці & 17 & $9,91 \pm 0,19$ & $9,60 \pm 0,20$ & 3,43 & $<0,01$ \\
\hline & Дівчата & 12 & $11,38 \pm 0,14$ & $11,03 \pm 0,14$ & 3,79 & $<0,01$ \\
\hline \multirow{2}{*}{11 клас } & Хлопці & 10 & $9,81 \pm 0,16$ & $9,02 \pm 0,07$ & 5,21 & $<0,001$ \\
\hline & Дівчата & 22 & $11,14 \pm 0,17$ & $10,75 \pm 0,20$ & 3,29 & $<0,01$ \\
\hline \multicolumn{7}{|c|}{ Бiz на 60 м (c) } \\
\hline \multirow{2}{*}{10 клас } & Хлопці & 17 & $9,12 \pm 0,10$ & $8,83 \pm 0,06$ & 3,97 & $<0,01$ \\
\hline & Дівчата & 12 & $11,18 \pm 0,26$ & $10,12 \pm 0,21$ & 8,18 & $<0,001$ \\
\hline \multirow{2}{*}{11 клас } & Хлопці & 10 & $9,09 \pm 0,12$ & $8,90 \pm 0,10$ & 3,05 & $<0,05$ \\
\hline & Дівчата & 22 & $11,00 \pm 0,26$ & $10,67 \pm 0,23$ & 3,70 & $<0,001$ \\
\hline \multicolumn{7}{|c|}{ Поперечний шпагат (см) } \\
\hline \multirow{2}{*}{10 клас } & Хлопці & 17 & $29,71 \pm 2,44$ & $26,53 \pm 2,60$ & 2,81 & $<0,05$ \\
\hline & Дівчата & 12 & $22,33 \pm 3,65$ & $16,92 \pm 2,89$ & 6,13 & $<0,001$ \\
\hline \multirow{2}{*}{11 клас } & Хлопці & 10 & $31,10 \pm 3,04$ & $27,90 \pm 3,14$ & 4,95 & $<0,001$ \\
\hline & Дівчата & 22 & $20,32 \pm 2,23$ & $17,59 \pm 1,94$ & 2,47 & $<0,05$ \\
\hline
\end{tabular}

вправ кросфіту, встановлено, що у школярів основних груп, переважно, тенденція розрізнень залишилась незмінною, у порівнянні з вихідними даними.

Досліджуючи показники учнів контрольних груп після експерименту, встановлено, що вони також дещо покращилися, однак, ці зміни не суттєві та не достовірні ( $>0,05)$. Так, приріст результатів варіював в межах від 0,3\% до 9,4\%. Слід зазначити, що за віком та статтю не виявлено змін у порівнянні з початковими даними.

При порівнянні повторних даних школярів основних та контрольних груп (табл. 2) встановлено значне превалювання результатів основних груп над контрольними. Слід зазначити, що достовірні відмінності спостерігаються за показниками піднімання прямих ніг у висі школярів 11-го класу $(p<0,05)$; бігу на місці з інтенсивністю 70\% від максимальної до вираженого стомлення школярів 10-11-х класів ( $<<0,05 ; 0,001)$; «човникового» бігу 449 м хлопців 11-го класу ( $p<0,001)$; бігу на 60 м ді- вчат 10-го класу $(p<0,01)$ та поперечного шпагату дівчат 11-го класу $(p<0,05)$.

Визначаючи рівень фізичної підготовленості учнів старшого шкільного віку після впровадження в процес фізичного виховання варіативного модуля «Кросфіт», виявлено, що на фоні значного і достовірного покращення результатів, він підвищився на 1 бал і став дорівнювати оцінці 4 бали, що свідчить про «вище за середній» рівень. Так, показники рівня розвитку сили, витривалості, спритності та гнучкості в середньому відповідають оцінці - 4 бали («вище за середній» рівень), швидкісних здібностей - 3 бали («середній» рівень). Слід зазначити, що у досліджуваних контрольних групах показники залишились незмінні, тобто зміни на оціночній шкалі не спостерігаються.

Таким чином, результати дослідження свідчать про позитивну динаміку показників фізичної підготовленості учнів 16-17-ти років основних груп під впливом вправ кросфіту. 
Таблиця 2

Порівняння показників фізичної підготовленості учнів основних та контрольних груп після експерименту

\begin{tabular}{|c|c|c|c|c|c|c|c|}
\hline \multirow{3}{*}{ Класи } & \multirow{3}{*}{ Стать } & \multicolumn{4}{|c|}{ Групи } & \multirow{3}{*}{$\mathrm{t}$} & \multirow{3}{*}{$\mathrm{p}$} \\
\hline & & $\mathrm{n}$ & Основні & $\mathrm{n}$ & Контрольні & & \\
\hline & & \multicolumn{4}{|c|}{ Показники $\bar{X} \pm \mathrm{m}$} & & \\
\hline \multicolumn{8}{|c|}{ Піднімання прямих ніг у висі (кількість разів) } \\
\hline \multirow{2}{*}{10 клас } & Хлопці & 17 & $17,88 \pm 2,11$ & 10 & $13,70 \pm 1,34$ & 1,67 & $>0,05$ \\
\hline & Дівчата & 12 & $12,17 \pm 2,06$ & 11 & $7,91 \pm 1,31$ & 1,74 & $>0,05$ \\
\hline \multirow{2}{*}{11 клас } & Хлопці & 10 & $19,80 \pm 1,53$ & 17 & $15,12 \pm 0,86$ & 2,67 & $<0,05$ \\
\hline & Дівчата & 22 & $14,14 \pm 0,93$ & 16 & $10,19 \pm 1,25$ & 2,54 & $<0,05$ \\
\hline \multicolumn{8}{|c|}{ Біг на місці з інтенсивністю 70\% від максимальної до виражсеного стомлення (с) } \\
\hline \multirow{2}{*}{10 клас } & Хлопці & 17 & $125,20 \pm 1,00$ & 10 & $121,04 \pm 1,57$ & 2,23 & $<0,05$ \\
\hline & Дівчата & 12 & $42,90 \pm 1,21$ & 11 & $33,85 \pm 1,24$ & 5,22 & $<0,001$ \\
\hline \multirow{2}{*}{11 клас } & Хлопці & 10 & $139,59 \pm 0,66$ & 17 & $131,24 \pm 1,53$ & 5,01 & $<0,001$ \\
\hline & Дівчата & 22 & $40,17 \pm 2,29$ & 16 & $34,31 \pm 1,70$ & 2,05 & $<0,05$ \\
\hline \multicolumn{8}{|c|}{ «Човниковий» біг $4 \times 9$ м (c) } \\
\hline \multirow{2}{*}{10 клас } & Хлопці & 17 & $9,60 \pm 0,20$ & 10 & $9,98 \pm 0,11$ & 1,68 & $>0,05$ \\
\hline & Дівчата & 12 & $11,03 \pm 0,14$ & 11 & $11,31 \pm 0,23$ & 1,07 & $>0,05$ \\
\hline \multirow{2}{*}{11 клас } & Хлопці & 10 & $9,02 \pm 0,07$ & 17 & $9,81 \pm 0,12$ & 5,49 & $<0,001$ \\
\hline & Дівчата & 22 & $10,75 \pm 0,20$ & 16 & $11,29 \pm 0,24$ & 1,76 & $>0,05$ \\
\hline \multicolumn{8}{|c|}{ Біг на 60 м (c) } \\
\hline \multirow{2}{*}{10 клас } & Хлопці & 17 & $8,83 \pm 0,06$ & 10 & $9,01 \pm 0,12$ & 1,35 & $>0,05$ \\
\hline & Дівчата & 12 & $10,12 \pm 0,21$ & 11 & $11,35 \pm 0,37$ & 2,92 & $<0,01$ \\
\hline \multirow{2}{*}{11 клас } & Хлопці & 10 & $8,90 \pm 0,10$ & 17 & $9,13 \pm 0,15$ & 1,30 & $>0,05$ \\
\hline & Дівчата & 22 & $10,67 \pm 0,23$ & 16 & $11,16 \pm 0,34$ & 1,22 & $>0,05$ \\
\hline \multicolumn{8}{|c|}{ Поперечний шпагат (см) } \\
\hline \multirow{2}{*}{10 клас } & Хлопці & 17 & $26,53 \pm 2,60$ & 10 & $28,80 \pm 4,72$ & 0,42 & $>0,05$ \\
\hline & Дівчата & 12 & $16,92 \pm 2,89$ & 11 & $20,55 \pm 3,87$ & 0,75 & $>0,05$ \\
\hline \multirow{2}{*}{11 клас } & Хлопці & 10 & $27,90 \pm 3,14$ & 17 & $31,35 \pm 2,92$ & 0,81 & $>0,05$ \\
\hline & Дівчата & 22 & $17,59 \pm 1,94$ & 16 & $23,38 \pm 1,96$ & 2,09 & $<0,05$ \\
\hline
\end{tabular}

\section{Висновки/ Дискусія}

За результатами досліджень встановлено, що вправи кросфіту у процесі фізичного виховання школярів 10-11-х класів сприяли покращенню рівня фізичної підготовленості. Так, розглядаючи зміни в показниках рівня розвитку максимальної динамічної сили м'язів черевного пресу, встановлене в основному значне покращення, як у хлопців, так і у дівчат основних груп, і ці відмінності статистично достовірні $(p<0,001)$. Вищезазначене підтверджується даними І.І. Земцової (2019), згідно яких виявлено, що при фізичних навантаженнях силової спрямованості відбувається гіпертрофія м'язів в результаті адаптаційно-трофічного впливу, що характеризується зростанням товщини та більш щільною упаковкою скорочувальних елементів м'язового волокна. Так, науковці Т. М. Кравчук, Т. В. Карпунець, І. В. Степаненко (2019) вказують, що впровадження в основну частину уроку функціональних вправ сприяло значному покращенню силових здібностей старшокласників.

Аналізуючи показники рівня розвитку витривалості, отримані після застосування варіативного модуля
«Кросфіт», визначено, що у школярів основних груп дані значно покращились та носять достовірний характер відмінностей $(p<0,001)$. Так, на думку О. М. Худолія (2008), це пояснюється тим, що у досліджуваному віці більш економними стають кисневі режими організму при фізичних навантаженнях, помітно збільшується можливість організму працювати «у борг», тобто підвищується анаеробна продуктивність.

Розглядаючи показники координованості рухів, отриманих після проведення педагогічного експерименту, виявлено, що у школярів старшого шкільного віку основних груп, вони значно покращились та носять достовірний характер відмінностей ( $<<0,01 ; 0,001)$. Вищезазначене підтверджується даними І. І. Земцової (2019), згідно яких визначено, що у період 16-17-ти років продовжується вдосконалення рухових координацій до рівня дорослих, а диференціювання м'язових зусиль досягає максимального рівня. Так, за даними В. А. Березовського (2016), встановлено, що під впливом уроків фізичної культури 3 елементами спортивного орієнтування суттєво покращились показники спритності школярів старших класів. 


\section{СЛОБОЖАНСЬКИЙ НАУКОВО-СПОРТИВНИЙ ВІСНИК}

Аналізуючи показники рівня розвитку частоти рухів, отриманих після впровадження вправ кросфіту, виявлено суттєве та достовірне покращення даних у школярів основних груп ( $<<0,05-0,001)$. Так, науковці Ж. К. Холодов, В. С. Кузнєцов (2008) стверджують, що заняття різними видами спорту позитивно впливають на розвиток швидкісних здібностей.

Аналізуючи показники рівня розвитку рухомості в кульшових суглобах, отриманих після експерименту, визначено, що у школярів основних груп, вони значно покращились та носять достовірний характер відмінностей ( $<<0,05 ; 0,001)$. За даними I. І. Земцової (2019), визначено, що в означеному віці ще не завершене окостеніння скелету, що забезпечує досить високий рівень рухливості та наявні значні резерви для поліпшення гнучкості, особливо під впливом систематичного, дозованого фізичного навантаження. Так, отримані нами дані узгоджуються 3 показниками В. У. Кренделєвої (2015), згідно яких спостерігаються позитивні зміни рівня розвитку гнучкості у юнаків та дівчат старших класів, під впливом оздоровчого фітнесу.

Таким чином, проведені дослідження свідчать про позитивний вплив запропонованих нами вправ кросфіту на рівень фізичної підготовленості школярів 10-11-х класів.

Перспективи подальших досліджень у даному напрямку можуть здійснюватися шляхом визначення рівня фізичного здоров'я школярів старших класів під впливом вправ кросфіту.

Конфлікт інтересів. Автори заявляють, що відсутній конфлікт інтересів, який може сприйматись таким, що може завдати шкоди неупередженості статті.

Джерела фінансування. Це дослідження фінансується за підтримки Європейської комісії. У статті відображено погляди лише авторів, і комісія не може нести відповідальність за будь-яке використання інформації, що міститься в ній.

\section{Список посилань}

1. Базилевич Н., Тонконог О. (2017), «Вплив засобів фітбол-аеробіки на фізичну підготовленість молодших школярів», Фізичне виховання, спорт і туристсько-краєзнавча робота в закладах освіти: зб. наук. праць: додаток до Гуманітарного віснику ДВНЗ «Переяслав-Хмельницький ДПУ імені Григорія Сковороди». Переяслав-Хмельницький (Київ. обл.), №31, С. 83-91. DOI:10.15330/fcult.31.3-8

2. Бала Т. М., Масляк І. П. (2014), «Динаміка показників рівня розвитку бистроти під впливом вправ чирлідингу», Вісник Чернігівського національного педагогічного університету. Сер.: педагогічні науки. Фізичне виховання та спорт, №118 (3), С. $14-$ 17. http://nbuv.gov.ua/UJRN/VchdpuPN_2014_118(3)_5

3. Березовський В. А. (2016), «Вплив уроків фізичної культури з елементами спортивного орієнтування на показники фізичної підготовленості та соматичного здоров'я учнів старших класів», Педагогіка формування творчої особистості у вищій і загальноосвітній школах, №48, С. 264-269.

4. Борисова Ю., Шкарупіло П. (2017), «Вплив занять капоейрою на фізичну підготовленість і соматичне здоров'я дітей 15-16-ти років», Спортивний вісник Придніпров'я: науково-практичний журнал, №1, С. 113-117. http://nbuv.gov.ua/UJRN/ svp_2017_1_22

5. Грабик Н., Грубар І., Якимишин Я. (2019), «Вплив позаурочних форм фізичного виховання на фізичний стан учнів 9-10 років», Актуальні проблеми розвитку спорту для всіх: досвід, досягнення, тенденції: матеріали VI Міжнародної науково-практичної конференції, Тернопіль, С. 7-14.

6. Єлісєєва Д. С. (2015), «Інноваційна технологія зміцнення здоров'я дітей старшого шкільного віку», Спортивний вісник Придніпров'я. Дніпропетровськ: ДДІФКіС, №2, С. 59-64.

7. Земцова І. І. (2019), Спортивна фізіологія: навчальний посібник. Київ, 207 с.

8. Кравчук Т. М., Карпунець Т. В., Степаненко, І. В. (2019), «Функціональне тренування як засіб розвитку силових здібностей учнів старших класів», Технології збереження здоров'я, реабілітація і фізична терапія: зб. ст. ХІІ Міжнар. наук. конф., Харків, С. $132-136$.

9. Кренделєва В. У. (2015), «Вплив оздоровчого фітнесу на рівень фізичної підготовленості учнів старших класів», Молодий вчений, №3 (18), С. 175-178.

10. Мамешина М. А. (2020), «Диференціація змісту навчальних занять з фізичного виховання з урахуванням показників фізичного здоров'я та фізичної підготовленості школярів 7-9-х класів», Слобожанський науково-спортивний вісник, № 6 (74), С. $25-31$.

11. Масляк І. П. (2017), «Вплив аеробіки силової спрямованості на стан кардіореспіраторної системи школярів старших класів», Науковий часопис НПУ імені М. П. Драгоманова, №1 (82), С. 35-38.

12. Романенко В. О. (2005), Диагностика двигательных способностей: учеб. пособие. Донецк: ДонНУ, 290 с.

13. Сергієнко Л. П. (2001), Тестування рухових здібностей школярів. Київ: Олімпійська література, 439 с.

14. Сергієнко Л. П. (2010), Спортивна метрологія: теорія і практичні аспекти: підручник. К.: КНТ, 776 с.

15. Суворова Т. І., Мороз М. С., Карабанов А. Г. (2011), «Вплив занять з атлетичної гімнастики на фізичну підготовленість учнів старших класів», Молодіжний науковий вісник. Молодіжний науковий вісник. Розділ 1. Фізична культура, фізичне виховання різних груп населення, №6, С. 13-16.

16. Фізична культура в школі: навчальна програма для 10-11 класів закладів загальної середньої освіти (2019). Київ: Літера лтД, $192 \mathrm{c.}$

17. Холодов Ж. К., Кузнецов В. С. (2008), Теория и методика физического воспитания и спорта: учеб. пособие для студ. высш. учеб. завед. Москва: Академия, 479 с. $406 \mathrm{c}$.

18. Худолій О. М. (2008), Загальні основи теорії і методики фізичного виховання: навч. посіб. 2-е вид., випр. Харків: ОВС,

19. Цимбалюк Ю. В., Мірошниченко В.І.(2018), «Вплив занять спортивною гімнастикою на фізичну підготовленість та адаптаційні можливості серцево-судинної системи хлопчиків 7-8 років», Український журнал медицини, біології та спорту, Т. 3, № 4, C. 231-236. http://nbuv.gov.ua/UJRN/ujmbs_2018_3_4_45

20. Ягодзінський В. П., Русанівський С. В., Безпалий С. М., Запорожанов О. В., Юр'єв С. О., Штома В. Д. (2020), «Розвиток силових якостей у курсантів у процесі занять за системою «Кросфіт»», Науковий часопис НПУ імені М. П. Драгоманова: зб. наук. пр. Київ: Вид-во НПУ імені М. П. Драгоманова, №2 (122), С. 198-201.

Петрова, А. (2021), «Вплив вправ кросфіту на рівень фізичної підготовленості школярів старшого шкільного віку»
Слобожанський науково-спортивний вісник, № 2(82), С. 63-69, doi:10.15391/snsv.2021-2.010 
21. Galimova A., Kudryavtsev M., Galimov G., Osipov A., Astaf'ev N., Zhavner T., et al. (2018), «Increase in power striking characteristics via intensive functional training in CrossFit», Journal of Physical Education and Sport, vol. 18 (2), p. 585-591. DOI: 10.7752/jpes.2018.02085

22. Krivoruchko N., Masliak I., Bala T., Skripka I., Honcharenko V. (2018), "The influence of cheerleading exercises on the demonstration of strength and endurance of 15-17-year-olds girls", Physical education of students, vol. 22 (3), p. 127-33. DOI: $10.15561 / 20755279.2018 .0303$

23. Kolomiitseva O., Prykhodko I., Prikhodko A., Anatskyi R., Turchynov A., Fushev S., Hunbina S., Garkavyi O. (2020), «Efficiency of Physical Education of University Students Based on the Motivation Choice of the CrossFit Program», Physical Activity Review, vol. 8 , p. 26-38.

24. Sibley B. A. (2012), «Using Sport Education to Implement a CrossFit Unit», Journal of Physical Education, Recreation \& Dance, vol. 83 (8), p. 42-48. DOI:10.1080/07303084.2012.10598829

25. Smith M. M., Sommer A. J., Starkoff B. E., Devor S. T. (2013), «Crossfit-based high-intensity power training improves maximal aerobic fitness and body composition», Journal of Strength and Conditioning Research, vol. 27 (11), p. 3159-3172. DOI:10.1519/ JSC.0b013e318289e59f

Стаття надійшла до редакції: 29.03.2021 р.

Опубліковано: 26.04.2021 р.

Аннотация. Ангелина Петрова. Влияние упражнений кроссфита на уровень физической подготовленности школьников старшего школьного возраста. Цель: определить степень изменения уровня физической подготовленности школьников 10-11-х классов под влиянием упражнений кроссфита. Материал и методы: теоретический анализ и обобщение научно-методической литературы, педагогическое тестирование, педагогический эксперимент и методы математической статистики. Для определения уровня развития физических качеств школьников 10-11-х классов использовались тесты: поднимание прямых ног в висе (количество раз); бег на месте с интенсивностью 70\% от максимальной до выраженного утомления (c); «челночный» бег 449 м (c); бег на 60 м (c); поперечный шпагат (см). Исследуемые результаты сравнивались с нормативными оценками и оценивались определенным количеством баллов. Статистический анализ: материалы исследования обрабатывались с использованием лицензированной программы Ехсеl. В исследовании приняли участие 113 школьников 10-11-х классов. Результаты: в начале учебного года осуществлено констатирующее исследование, согласно которому установлен “средний» уровень (3 балла) физической подготовленности у школьников 16-17-ти лет. По результатам первичного исследования ученики были разделены на основные и контрольные группы для проведения формирующего эксперимента. Школьники контрольных групп занимались лишь по общепринятой государственной программе по физической культуре для 10-11 классов учреждений общего среднего образования, а учебный процесс по физическому воспитанию школьников основных групп был дополнен вариативным модулем «Кроссфит». Согласно исследованиям, полученных после проведения педагогического эксперимента, установлено, что у школьников основных групп уровень физической подготовленности повысился до «выше среднего» (4 балла), а у исследуемых контрольных группах изменения на оценочной шкале не обнаружены. В возрастном аспекте определено, в основном, улучшение результатов $C$ возрастом, как у школьников основных, так и контрольных группах $(p>0,05)$. По половому признаку обнаружено, преимущественно, достоверное превалирование данных юношей над показателями девушек $(p<0,05-0,001)$. Выводы: выявлено положительное влияние упражнений кроссфита на уровень физической подготовленности учащихся 10-11-х классов основных групп.

Ключевые слова: вариативный модуль, кроссфит, ученики старших классов, физическая подготовленность, уроки физической культуры, двигательная активность.

Abstract. Petrova Angelina. Effect of CrossFit exercises on the level of physical fitness of high school-age pupils. Purpose: to determine the degree of change in the level of physical fitness of the 10th-11th grade pupils under the influence of CrossFit exercises. Material and methods: theoretical analysis and generalization of scientific-methodological literature; pedagogical testing, pedagogical experiment, and methods of mathematical statistics. The tests were used to determine the level of physical fitness of the 10th-11th grade pupils: raising straight legs in a hanging (number of times); running in place with the intensity of $70 \%$ from maximum to pronounced fatigue (s); "shuttle" run 4-9 $\mathrm{m}(\mathrm{s})$; run $60 \mathrm{~m}(\mathrm{~s})$ and cross split $(\mathrm{cm})$. The studied results were compared to norms and evaluated with a certain number of points. Statistical analysis: the study materials were processed using the licensed program Excel. The research involved 113 pupils of the 10th-11th grades. Results: at the beginning of the school year, the stating research was carried out, according to which the "average" level (3 points) of physical fitness among 16-17-year-old pupils was established. According to the results of the primary research, pupils were divided into main and control groups for conducting the formative experiment. Pupils of the control groups were engaged by the generally accepted state program on physical education for 10-11 grades of general secondary education institutions, and the educational process on physical education of pupils of the main groups was supplemented by the variable module "CrossFit". According to researches obtained after the pedagogical experiment, it was established that the level of physical fitness increased to "above the average" (4 points) in pupils of the main groups, and changes weren't found on the assessment scale in the researched control groups. In the age aspect, there is mainly the improvement in results with age, both in main and control groups $(p>0,05)$. The reliable prevarication of the data of boys, over the indicators of girls, was revealed, mainly, in the article $(p<0,05-0,001)$. Conclusions: the positive impact of CrossFit exercises on the level of physical fitness of the 10th-11th grade pupils of main groups was revealed.

Keywords: variable module, CrossFit, high school pupils, physical fitness, physical culture lessons, motor activity.

\section{References}

1. Bazylevych, N., Tonkonoh, O. (2017), «The effect of fitball aerobics on the physical fitness of younger pupils», Fizychne vykhovannia, sport i turystsko-kraieznavcha robota $v$ zakladakh osvity: zb. nauk. prats: dodatok do Humanitarnoho visnyku DVNZ «Pereiaslav-Khmelnytskyi DPU imeni Hryhoriia Skovorody». Pereiaslav-Khmelnytskyi (Kyiv. obl.), №31, pp. 83-91. DOI:10.15330/ fcult.31.3-8. (in Ukr.).

2. Bala, T. M., Masliak, I. P. (2014), «The dynamics of indicators of the level of speed development under the influence of cheerleading exercises", Visnyk Chernihivskoho natsionalnoho pedahohichnoho universytetu. Ser.: pedahohichni nauky. Fizychne vykhovannia ta sport, №118 (3), pp. 14-17. http://nbuv.gov.ua/UJRN/VchdpuPN_2014_118(3)__5. (in Ukr.). 


\section{СЛОБОЖАНСЬКИЙ НАУКОВО-СПОРТИВНИЙ ВІСНИК}

3. Berezovskyi, V. A. (2016), "The influence of physical culture lessons with elements of sports orientation on indicators of physical fitness and somatic health of high school pupils», Pedahohika formuvannia tvorchoi osobystosti u vyshchii i zahalnoosvitnii shkolakh, №48, pp. 264-269. (in Ukr.).

4. Borysova, Yu., Shkarupilo, P. (2017), «The impact of capoeira on physical fitness and somatic health of 15-16-year-old children», Sportyvnyi visnyk Prydniprovia: naukovo-praktychnyi zhurnal, №1, pp. 113-117. http://nbuv.gov.ua/UJRN/svp_2017_1_22. (in Ukr.).

5. Hrabyk, N., Hrubar, I., Yakymyshyn, Ya. (2019), «The impact of extra-time forms of physical education on the physical state of 9-10-year-old pupils», Aktualni problemy rozvytku sportu dlia vsikh: dosvid, dosiahnennia, tendentsii: materialy VI Mizhnarodnoi naukovo-praktychnoi konferentsii, Ternopil, pp. 7-14. (in Ukr.).

6. Ielisieieva, D. S. (2015), "The innovative technology to promote the health of older school children», Sportyvnyi visnyk Prydniprovia. Dnipropetrovsk: DDIFKiS, №2, pp. 59-64. (in Ukr.).

7. Zemtsova, I. I. (2019), Sportyvna fiziolohiia: navchalnyi posibnyk [Sports physiology], Kyiv, 207 p. (in Ukr.).

8. Kravchuk, T. M., Karpunets, T. V., Stepanenko, I. V. (2019), «Functional training as a means of developing the strength of high school pupils», Tekhnolohii zberezhennia zdorovia, reabilitatsiia i fizychna terapiia: zb. st. XII Mizhnar. nauk. konf., Kharkiv, pp. 132-136. (in Ukr.).

9. Krendelieva, V. U. (2015), "The impact of wellness fitness on the level of physical fitness of high school pupils", Molodyi vchenyi, №3 (18), pp. 175-178. (in Ukr.).

10. Mameshyna, M. A. (2020), "The differentiation of the content of physical education classes taking into account the indicators of physical health and physical fitness of the 7th-9th grade pupils», Slobozhanskyi naukovo-sportyvnyi visnyk, № 6 (74), pp. 25-31. (in Ukr.).

11. Masliak, I. P. (2017), «The influence of power aerobics on the state of the cardiorespiratory system of high school pupils», Naukovyi chasopys NPU imeni M. P. Drahomanova, №1 (82), pp. 35-38. (in Ukr.).

12. Romanenko, V. O. (2005), Diagnostika dvigatelnykh sposobnostei [The diagnosis of motor abilities]: ucheb. posobie. Donetck: DonNU, 290 p. (in Russ.).

13. Serhiienko, L. P. (2001), Testuvannia rukhovykh zdibnostei shkoliariv [Testing the motor abilities of pupils], Kyiv: Olimpiiska literatura, 439 p. (in Ukr.).

14. Serhiienko, L. P. (2010), Sportyvna metrolohiia [Sports metrology]: teoriia i praktychni aspekty: pidruchnyk, K.: KNT, 776 p. (in Ukr.).

15. Suvorova, T. I., Moroz, M. S., Karabanov, A. H. (2011), «The impact of athletic gymnastics classes on physical fitness of high school pupils», Molodizhnyi naukovyi visnyk. Molodizhnyi naukovyi visnyk. Rozdil 1. Fizychna kultura, fizychne vykhovannia riznykh hrup naselennia, №6, pp. 13-16. (in Ukr.).

16. Fizychna kultura v shkoli: navchalna prohrama dlia 10-11 klasiv zakladiv zahalnoi serednoi osvity [Physical culture in school: curriculum for 10-11 grades of general secondary education] (2019), Kyiv: Litera LTD, 192 p. (in Ukr.).

17. Kholodov, Zh. K., Kuznetcov, V. S. (2008), Teoriia i metodika fizicheskogo vospitaniia i sporta [The theory and methods of physical education and sport]: ucheb. posobie dlia stud. vyssh. ucheb. zaved. Moskva: Akademiia, 479 p. (in Russ.).

18. Khudolii, O. M. (2008), Zahalni osnovy teorii i metodyky fizychnoho vykhovannia [Fundamentals of the theory and methods of physical education]: navch. posib. 2-e vyd., vypr. Kharkiv: OVS, 406 p. (in Ukr.).

19. Tsymbaliuk, Yu. V., Miroshnychenko, V. I. (2018), «The impact of gymnastics on physical fitness and adaptability of the cardiovascular system of 7-8-year-old boys», Ukrainskyi zhurnal medytsyny, biolohii ta sportu, T. 3, № 4, pp. 231-236. http://nbuv.gov. ua/UJRN/ujmbs_2018_3_4_45. (in Ukr.).

20. lahodzinskyi, V. P., Rusanivskyi, S. V., Bezpalyi, S. M., Zaporozhanov, O. V., Yuriev, S. O., Shtoma, V. D. (2020), «The development of strength qualities of cadets in the course of classes on the CrossFit system", Naukovyi chasopys NPU imeni M. P. Drahomanova. Zb. nauk. pr. Kyiv: Vyd-vo NPU imeni M. P. Drahomanova, №2 (122), pp. 198-201. (in Ukr.).

21. Galimova, A., Kudryavtsev, M., Galimov, G., Osipov, A., Astaf'ev, N., Zhavner, T., et al. (2018), «Increase in power striking characteristics via intensive functional training in CrossFit», Journal of Physical Education and Sport, vol. 18 (2), pp. 585-591. DOI:10.7752/jpes.2018.02085. (in Eng.).

22. Krivoruchko, N., Masliak, I., Bala, T., Skripka, I., Honcharenko, V. (2018), «The influence of cheerleading exercises on the demonstration of strength and endurance of 15-17-year-olds girls», Physical education of students, Vol. 22 (3), pp. 127-33. DOI:10. 15561/20755279.2018.0303. (in Eng.).

23. Kolomiitseva, O., Prykhodko, I., Prikhodko, A., Anatskyi, R., Turchynov, A., Fushev, S., Hunbina, S., Garkavyi, O. (2020), «Efficiency of Physical Education of University Students Based on the Motivation Choice of the CrossFit Program», Physical Activity Review, vol. 8, pp. 26-38. (in Eng.).

24. Sibley, B. A. (2012), "Using Sport Education to Implement a CrossFit Unit», Journal of Physical Education, Recreation \& Dance, Vol. 83 (8), pp. 42-48. DOI:10.1080/07303084.2012.10598829. (in Eng.).

25. Smith, M. M., Sommer, A. J., Starkoff, B. E., Devor, S. T. (2013), «Crossfit-based high-intensity power training improves maximal aerobic fitness and body composition", Journal of Strength and Conditioning Research, Vol. 27 (11), pp. 3159-3172. DOI:10.1519/ JSC.0b013e318289e59f. (in Eng.).

Received: 29.03.2021.

Published: 26.04.2021.

\section{Відомості про авторів / Information about the Authors}

Петрова Ангеліна Сергіївна: викладач кафедри теорії та методики фізичного виховання; Харківська державна академія фізичної культури: вул. Клочківська 99, Харків, 61058, Україна.

Петрова Ангелина Сергеевна: преподаватель кафедры теории и методики физического воспитания; Харьковская государственная академия физической культуры: ул. Клочковская, 99, г. Харьков, 61058, Украина.

Anhelina Petrova: teacher of the department of theory and methods of physical education; Kharkiv State Academy of Physical Culture: Klochkivska str. 99, Kharkiv, 61058, Ukraine.

ORCID: https://orcid.org/0000-0001-6400-8624

E-mail: petrovaangelina@ukr.net 